\title{
E-Learning and Transformative Learning in Adult Training
}

\author{
Evgenia Pavlakou (Corresponding author) \\ Phd Candidate, Athens University of Economics and Business \\ Dept. of Marketing and Communication
}

Tel: 30-210-764-4853Ｅ-mail: epavlakou@gnosi.gr

\begin{abstract}
Konstantinos Kalachanis
Phd in Philosophy, National and Kapodistrian University of Athens Research Fellow, Nea Gnosi, Professional and Vocational Training Tel: 30-210-902-9780 E-mail:kkalachan@phys.uoa.gr
\end{abstract}

\author{
Sophia Kefali \\ ,M.Sc. in Educational Sciences \\ Nea Gnosi, Professional and Vocational Training \\ Tel: 30-210-902-9780Ｅ-mail: sophiakef@hotmail.gr
}

\begin{abstract}
Eleni Tsiouni
Sociologist, M.Sc. in Criminology,

Training \& Development Specialist / Project Manager Nea Gnosi

Professional and Vocational Training
\end{abstract}

Tel: 30-210-902-9780 E-mail: lenatsiouni@yahoo.gr

Received: Jan. 25, 2019 Accepted: March 14, 2019 Published: May 1, 2019

doi:10.5296/jse.v9i2.14265 URL: https://doi.org/10.5296/jse.v9i2.14265 


\title{
Macrothink
}

\begin{abstract}
Transformative learning refers to the process of transforming frameworks through which adults interpret the experiences, values, feelings, and shape their actions and living conditions, combined with the cultural context in which they are socialized. In this process the adult re-evaluates the experiences he has gained since his childhood, resulting in a new knowledge through critical thinking. Transformative learning is applied to adult education where the aim is to acquire new professional skills based on the needs of learners. The ability to apply distance learning asynchronously releases it from spatial or temporal constraints, making it suitable for the implementation of transformative learning. The trainer can take advantage of the technological applications (video, presentations, etc. asynchronous communication, and e mail) and authoritative scientific sources of the internet. This activates the trainee in a heuristic course towards the knowledge that will move his interest and will change his / her perceptual systems by leading him / herself into self-realization. Therefore, the use of distance learning in adult education is fully in line with the principles of transforming learning.
\end{abstract}

Keywords: transformative learning, adult education, e - learning 


\section{Mll Macrothink}

\section{Introduction}

Adult education intends to help learners to develop new skills in order to meet practical and working needs. It also incorporates the principles of transforming learning, which aims to change the established perceptions of learners. In the present study we will first examine the way in which man interprets reality, based on the sensory perception of the world, but also on the mental processing of the stimuli on the basis of which his attitudes of life are shaped. Then will be analyze the advantages of transforming learning in adult education, especially when using distance learning methods. Finally, the role of the trainer will be discussed

\section{The perception of reality by man}

The way in which man perceives reality had been studied by ancient Greek philosophers who claimed that human senses have limited capabilities in understanding reality. According to the Presocratic philosopher Xenophanes $\left(5^{\text {th }}\right.$ cen. B.C. $)$ which means that every human being has an opinion (DK A 24, 4) is not sufficient to describe the reality as a whole. Indeed, human senses have limited capabilities, which is evident in the electromagnetic spectrum, from which we perceive a limited part 400-700nm (Fig. 1)

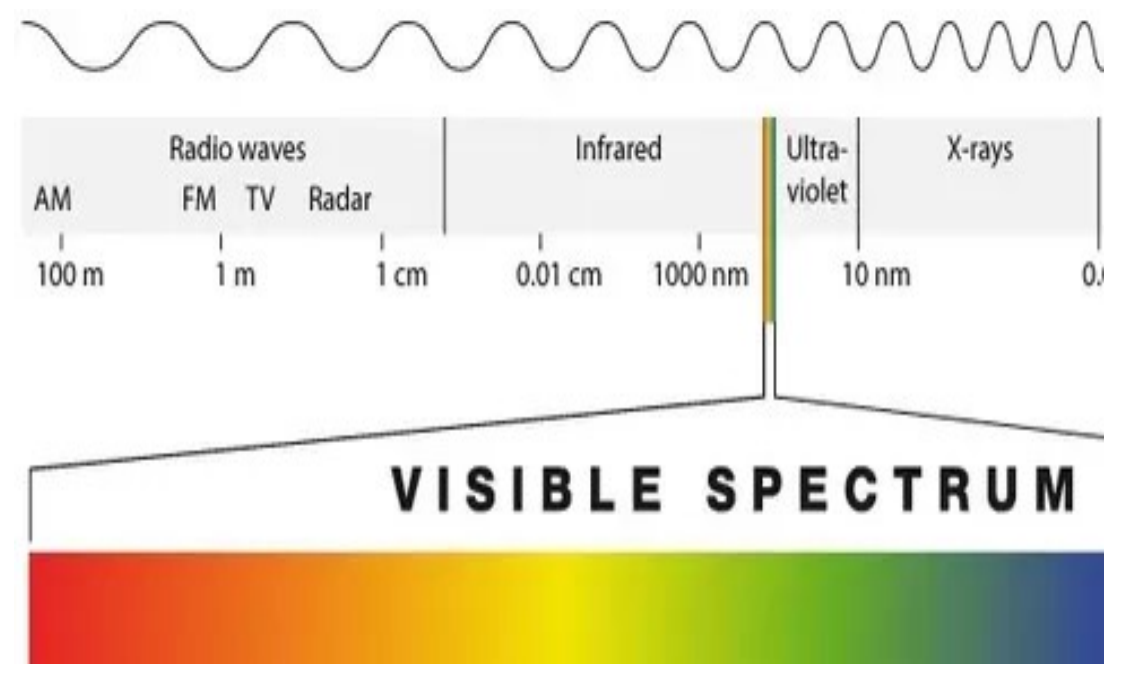

Fig. 1. man only perceives the visible light from the electromagnetic spectrum. The rest is detected by technological devices

Source: https://www.quora.com/

Moreover in the platonic dialogue Theaetetus (152 D) Plato considers man as an observer whose, whose sensory organs, in combination with the mental process, shape the perception of reality (Kalachanis, 2014). Indeed Plato correctly describes the process of intelligence, which transforms sensory data into learning. Besides, the perception of reality by man is not only based on the data of the senses but mainly on their processing by the intellect (Carbon, 2014), based on which reference frameworks are created (mental tools of interpretation of reality) and the attitude of life is shaped. It should be noted here that the shaping of human personality largely depends on the a priori notions which, according to the German philosopher I. Kant, are the knowledge derived from the inherent ideas preceding the 
experience (for which it was noteworthy Plato spoke, referring to the world of Ideas). There is also the knowledge that comes from the experience, which also according to Kant is characterized as a posteriori. Therefore, the personality of man is shaped, on the one hand, on the basis of the experience he derives, but also from his innate ideas. Based on this interaction he interprets the world around him as well as his experiences.

This platonic theory is directly related to the perception of Mezirow, who argues that our perceptual ability plays a vital role in shaping the system of values and perceptions governing our everyday lives (Rogers, 1991).

\section{Transformative Learning in Adult Education}

Aristotle had written in his Metaphysics $(980 \mathrm{a}, 21)$ that human beings by their nature have a basic need to learn. In modern Pedagogics is supported the view that human should actually become a lifelong learner not only because of the curiosity about knowledge that characterizes it, but also because it is imposed by living conditions (globalization) (Jarvis, 2004 p. 38).

It is supported that the roots of Transformative Learning (TL) can be traced in the theory of Paulo Freire who rejected the model the dominant teacher centred pedagogical system where the teacher communicated knowledge (deposits into the brains) who actually were only passive listeners without any ability to interact (Freire, 1970, p. 72) The role of transformative learning refers to the process of transforming frameworks through which adults interpret their acquired experiences, values, feelings and shape their actions and living conditions, combined with the cultural context within which they are socialized (Kokkos, 2005). Actually this means that the learner has to reach self-knowledge and then transform him/herself (Jarvis, 2003). This is why Taylor (1998, p. 13) considered the procedure of transformation as a life-long process of coming to undertand throught the reflection of the psychic structures (ego, persona etc) that make up one's identity. Mezirow who established the theory of TL points out that the perceptions change occurs in a number of ways, such as reading a book, adopting a different view, but also contacting different social groups and cultures (Mezirow, 1997). In this context is supported the view that the key elements of TL are the following (Kokkos, 2010):

- Editing an existing view. This is a process by which we improve or change a particular view we have adopted. However, there is no question in the present case of the wider system of mental habits.

- The second type of learning consists of adopting a new view, which is however relevant and compatible with what the person has already embraced. In this case the intellect extends to other objects, but without changing the basic parameters on which it forms its interpretative frameworks.

- The radical transformation of a view, where perceptions and values are now completely altered. 
- The transformation of a cognitive habit or the entire system of mental habits, where the way of interpreting reality changes.

TL is widely and successfully implemented in adult education, where the main objective is to acquire new vocational skills and meet practical needs (see Kokkos, 2005, pp. 48-49.) However, this is not always possible, as (Kokkos, 2008 p. 85), because of their experiences and abundance of experience. Therefore, it is obvious that the educational program should be shaped by the wishes and the expectations of learners who wish to be actively involved in the learning process (Kalogiannakis, et al. 2009). But what has to be considered is the fact that transformations to more advanced perceptions often occur after the age of 30 where there is a better awareness of psychological factors as well as individual and collective goals, and well developed logical and emotional skills (Mezirow, 1991, p. 193)

In this process, the adult guided by the trainer (Boyer et al., 2016) re-evaluates the beliefs he has adopted and the experiences he has gained since his childhood. Therefore, there is a first assessment of the accepted interpretative frameworks. Then, the pedagogical process leads to a new knowledge through critical thinking (Mezirow, 1990; Lintzeris, 2010, p. 96), with the final result of promoting the critical thinking of trainees (Scheele, 2015).

An important difficulty that arises in the process of transforming learning is the inability of adults to respond to the learning process and the resulting failure of educational goals. The reason is that adults already have established beliefs that are difficult to change (Kokkos, 2008); An important difficulty that arises in the process of transforming learning is the inability of adults to respond to the learning process and the resulting failure of educational goals. The reason is that adults already have established beliefs that are difficult to change (Barnard et al. 2013). This highlights the need for the educational program to be shaped by the wishes and expectations of trainees who wish to participate actively in the learning process (Kalogiannakis, et al., 2009), but also to provide them with a sufficient incentive. Every person has different perceptions and abilities, so the learning process must be personalized and tailored to the needs of each learner.

\section{E Learning, Transformative Learning and the role of the trainer}

Distance learning has been proved to be a great success in adult education, as it provides sophisticated tools and supervisory training tools such as online learning platforms (Pavlakou \& Kalachanis, 2018). Distance Learning takes place using asynchronous tele-learning systems, commonly known as "platforms", and includes a variety of course management tools, access tools to educational material resources, and synchronous and asynchronous communication tools. In particular, the advantages of using an asynchronous tele-learning platform can be summarized as follows: (Ministry of National Education and Religious Affairs, 2006, p.25).

- Ease of access to educational material through web pages.

- Support for the integration of multimedia information through image, audio and video files.

- Asynchronous communication through services such as e-mail, bulletin boards and 
discussion groups.

- Contemporary communication through services such as chat and video-conference teleconferencing.

- Support the learning process through tools to monitor student progress, search for self-assessment information and activities.

- Management of the course through recording management tools, on-line scoring and collection and grading of learners' grades.

- Help desk to support the trainer and trainee to provide facilities and answer questions.

Distance learning contributes to transforming learning as it has the following advantages:

- Promotes a learner-centered perspective, tailored to the needs of each learner, and given the trainer's ability to adapt his / her material at any time. It should be noted that not all learners have the same abilities, but they also have different ways of perceiving learning. B.C. some prefer listening while others read it.

- It provokes the learner's interest, as he urges him to think again about the perceptions he already has and potentially change them. Additionally, knowledge acquired is applied.

- The participation of trainees in the formation of the lesson, which includes moments of reflection and reflection, is promoted. In this process, the trainee can be asked about how he evaluates the content of the course, but also engages mentally and emotionally. Only with this kind of deep and substantial commitment can some permanent change occur.

- Community-centered perspective and group work (Gutierrez, 2013).

Following the presentation of the benefits of distance education in transforming learning, the role of the trainer should be discussed. The development of supervisory teaching tools enables the trainer to exploit the technological applications (video, presentations, etc. asynchronous communication, e-mail) and especially authoritative scientific sources of the internet in order to meet the needs of each trainee. This activates the trainee in a heuristic course towards knowledge (Vouzaxakis \& Georgiadi, 2013). Also the trainer should be encouraged to apply best practices in their work thus becoming actually learners (Borko, 2014). In this case the learner benefits to the fullest extent, as teaching has such characteristics as to motivate his interest and possibly change his / her systems of perceptions, leading him to self-realization. Although Cox (2017) points to another parameter that lies in together alone paradox where despite the fact that an individual may interact and meanwhile being connected with other adults however, he/she may have feelings of loneliness and isolation. Turkle (2011) points out that e learning creates the feeling of being "alone together" but on the other hand some users may benefit from it by "the comfort of connection without the demands of intimacy".

This means that the use of distance learning in adult education is fully in line with the principles of TL, as it includes the following parameters (Pavlakou \& Kalachanis, 2018): 
- Evaluating scientific sources, especially the Internet. The trainer must be scientifically trained and knowledgeable about his subject, but also be able to distinguish which sources are actually usable. It should be noted here that because of the development of the Internet, many embrace information that is intended to mislead. Therefore, transformational learning also has the meaning of the learner's correct orientation.

- Educational objectives can be changed at any time, depending on the quality of the course and the recruitment of the learners. Therefore, the teacher should have the flexibility to modify the material, depending on the educational objectives and the individual needs of the participants, which can be constantly changed.

- Interaction so that the lesson is interesting and promotes the interaction of the participants. New technologies offer this flexibility.

- Use applications such as skype, messenger, etc. so that it is in direct contact with the participants. In addition, eLearning platforms also provide the opportunity to create a forum for exchange of views among trainees. In this way, transformational learning finds scope, as perceptual change can be achieved through interaction.

Furthermore online training does not provide significant opportunities only to learners, but also to their trainers provided that it is governed by collaboration, content- and pedagogy-focused, and relevance. Their program also must be adapted to the circumstances, as a teacher has a lot of duties beyond teaching, such as homework. In this case an online interaction with his/her colleagues may be a very good chance of sharing ideas about the program and further professional development (Taylor, 2011; Smith, 2012).

From the above is clear that the role of the trainer, should not be limited just to the preparation and configuration of the training material, but also includes the assistance to the trainee in order to achieve self-realization. In fact, according to the theory of Andragogy, learning is by definition a process where adult experiences are constantly transformed and influenced by experiences, with the trainer learning how to learn "how to learn". Also Andragogy is a learning theory designed to address the particular needs of adults, and it is based on the idea that there are significant differences in learning characteristics between children and adults (Knowles, 1978 \& 1984). This creative course in which the instructor leads his student involves the inclusion of critical thinking, (Mezirow, 1990 \& Lintzeris, 2010, p. 96; Scheele, 2015). Also a well-designed online learning environment may boost self-directed learning since it provides the participants with the opportunity for team working as well working individually. Dede (2006) claims that the asynchronous nature of online learning removes the pressure of immediate response, allowing participants to take the time to reflect on new concepts before responding to prompts

\section{Conclusion}

It is evident from the above that distance learning, provided that it is implemented with the right tools, has all the prerequisites to serve the purposes of transforming learning and to change the perceptions of trainees. The role of the trainer in this respect is decisive as it is not limited to editing the teaching material, but should also take advantage of the technological 
tools that distance education offers in order to change the perceptions of his pupils. Of course, it should also take into account the difficulty of many adults from re-entering the learning process, but also their possible difficulty with the use of modern technology. Despite the difficulties, distance learning is fully in line with the principles of transforming learning.

\section{References}

Barnard, Y., Bradley, M.D., Hodgson, F., \& Lloyd, A.D. (2013). Learning to use new technologies by older adults: Perceived difficulties, experimentation behaviour and usability. Computers in Human Behavior, 29(4), 1715-1724. http://www.savie.qc.ca/BaseConnaissances/upload/pdf/2166_barnardetal_2013_learningtouse newtechnologiesbyolderadults

Vouzaxakis, G., \& Georgiadi, E. (2013). The use of Moodle platform as a tool for distance training of teachers of secondary education 7th International Conference in Open \& Distance Learning - November 2013, Athens, Greece-Proceedings.

Borko, H. (2004). Professional Development and Teacher Learning: Mapping the Terrain. Educational Researcher, 33(8), 3-15. https://doi.org/10.3102/0013189X033008003

Boyer, N. R., Maher, P. A., \& Kirkman, S. (2016). Transformative Learning in Online Settings. Journal of Transformative Education, 4(4), 335-361.

Carbon, C.C. (2014). Understanding human perception by human-made illusions, Frontiers in Human Neuroscience, 8, 566. https://doi.org/10.3389/fnhum.2014.00566

Cox, A. (2017). Adult Learning in Online Educative Spaces: A Constructive-

Developmental Perspective. Adult Education Research Conference. http://newprairiepress.org/aerc/2017/papers/6

Dede, C. (Ed.) (2006). Online professional development for teachers: emerging models and methods. Cambridge, MA: Harvard Education Press. https://eric.ed.gov/?id=ED568747

Diels, H. \& Kranz, W. (1951). Die Fragmente der Vorsokratiker, 1, 6th edn. Berlin: Weidmann.

Freire, P. (1970). Pedagogy on the Oppressed trans. Myra Bergman Ramos. New York: Continuum.

Gutierrez, K. (2013). E-Learning: Six Key Ingredients of Learner-centered eLearning Courses. Retrieved from: https://www.shiftelearning.com/blog/bid/301962/Six-Key-Ingredients-of-Learner-centered-e Learning-Courses.

Jarvis, P. (2004). Adult Education and Lifelong Learning, $3^{\text {rd }}$ edition,London \& New York. https://doi.org/10.4324/9780203561560

Kalachanis, K. (2014). The critics of senses in Plato's Theaetetus Philosophical Review Philosophein, Zitros Publications, 10, 115-126 (in greek) 
Kalogiannakis, M., Alafodimos, K., Vassilakis, K., Papachristos,D., Papadakis, St. \& Zafeiri, E. (2009). Adult Education and Lifelong Learning : A Greek Case Study. International Journal of Advanced Corporate Learning, 2(4), November 2009.

Knowles, M.S. (1978). The Adult Learner: A Neglected Species, 63 2nd Ed. Houston: Gulf.

Knowles M.S. (1984). Andragogy in action. San Fransisco, Jossey Bass.

Kokkos, A. (2005). Adult Training: detecting the field. Metechmio Publications, Athens, Greece (in Greek).

Kokkos, A. (2008). An Introduction in Adult Training. Volume 1. Hellenic Open University, Patra (in Greek).

Lintzeris. P. (2010). Transformative Learning Theory: Ability for a critical and emancipative turn in the practice of Adult Training. In. Vergidis, D. Kokkos, A. (eds) Adult Training: international approaches and greek routes, Metechmio Publications, Athens, Greece (in greek) (pp. 94-13).

Mezirow, J. \& Associates (eds.) (1990). Fostering Critical Reflection in Adulthood. San Francisco: Jossey-Bass.

Mezirow, J. (1991). Transformative Dimensions of Adult Learning. San Francisco: Jossey-Bass.

Mezirow, J. (1997). Transformative Learning: Theory to Practice. New directions for Adults and Continuing Education, 74, 5-12. https://doi.org/10.1002/ace.7401

Ministry of National Education and Religious Affairs (2006). Adult education 8. Distance Learning in Adult Education -Examples and cases of application. Athens (in greek).

Pavlakou, E. \& Kalachanis, K. (2018). Adult Education using the Moodle e-Learning Platform: The Role of the Trainer. Journal of Education \& Social Policy, 5(3), 105-109. https://doi.org/10.30845/jesp.v5n3p13

Plato, (1900). Theaetetus. ed. J. Burnet, Oxford, Clarendon Press.

Scheele, P. R. (2015). Transformative learning in higher education: Praxis in the field of Leadership change. Journal of Transformative Learning, 3(1), 5-12.

Rogers, A. (1991). Teaching adults in extension, Reading, Education in Development.

Smith, R. O. (2012). Fostering transformative learning online. In E. W. Taylor \& P. Cranton (Eds.), The handbook of transformative learning: theory, research, and practice (pp. 408422). San Francisco: Jossey-Bass.

Taylor, E. W. \& Snyder, M. J. (1998). The theory and practice of transformative learning: $\begin{array}{lllll}\text { critical review. } & \text { Information } & \text { Series } & \text { No } & 374 .\end{array}$ https://calpro-online.org/eric/docs/taylor/taylor_00.pdf

Taylor, J. M. (2011). Characteristics of effective online professional development: A case 


\section{Macrothink}

Journal of Studies in Education

ISSN 2162-6952 2019, Vol. 9, No. 2

study analysis of an online professional development course offered via Blackboard. (3501375 Ed.D.), University of Pittsburgh, Ann Arbor. http://d-scholarship.pitt.edu/10812/

Turkle, S. (2011). Alone together: Why we expect more from technology and less from each other. New York, NY, Basic Books. 